\title{
Ultrasound-based monitoring of cardiac output after off-pump coronary artery bypass grafting
}

\author{
Izotova N. N. ${ }^{1,2}$, Ilyina Y. U. ${ }^{1,2}$, Smetkin A. A. ${ }^{1,2}$, Fot E. V.1,2 Kuzkov V. V. ${ }^{1,2}$, Kirov M. Y. ${ }^{1,2}$
}

Department of Anesthesiology and Intensive Care Medicine, Northern State Medical University, Russian Federation

- Department of Anesthesiology and Intensive Care Medicine, City Hospital \#1 of Arkhangelsk, Russian Federation

\section{Background}

Recently, USCOM technique (Ultrasound Cardiac Output Monitor), using advanced Doppler method to assess cardiac output (CO), has become clinically available. However, this technique requires validation in different categories of patients. The aim of our study was to evaluate the accuracy of USCOM compared to prepulmonary thermodilution in patients after off-pump coronary artery bypass grafting (OPCAB).

\section{Methods}

We enrolled 33 patients who underwent elective OPCAB into an ongoing prospective observational study. The measurements of cardiac index $(\mathrm{CI})$ based on USCOM $\left(\mathrm{Cl}_{\mathrm{USCOM}}\right)$ and $\mathrm{Cl}$ determined by thermodilution using pulmonary artery catheter $\left(\mathrm{Cl}_{\mathrm{TD}}\right)$ were performed at seven stages during postoperative period. We calculated Spearman's rho coefficient to assess the correlation between $\mathrm{Cl}_{\mathrm{USCOM}}$ and $\mathrm{Cl}_{\mathrm{TD}}$. The agreement between methods was evaluated using Bland-Altman analysis with percentage error calculation using overall pairs of data and separately during mechanical ventilation (4 stages) and after tracheal extubation ( 3 stages). Additionally, we evaluated trending ability using four-quadrant plot and concordance index based on overall data and separately during mechanical ventilation and after tracheal extubation.

Fig.1

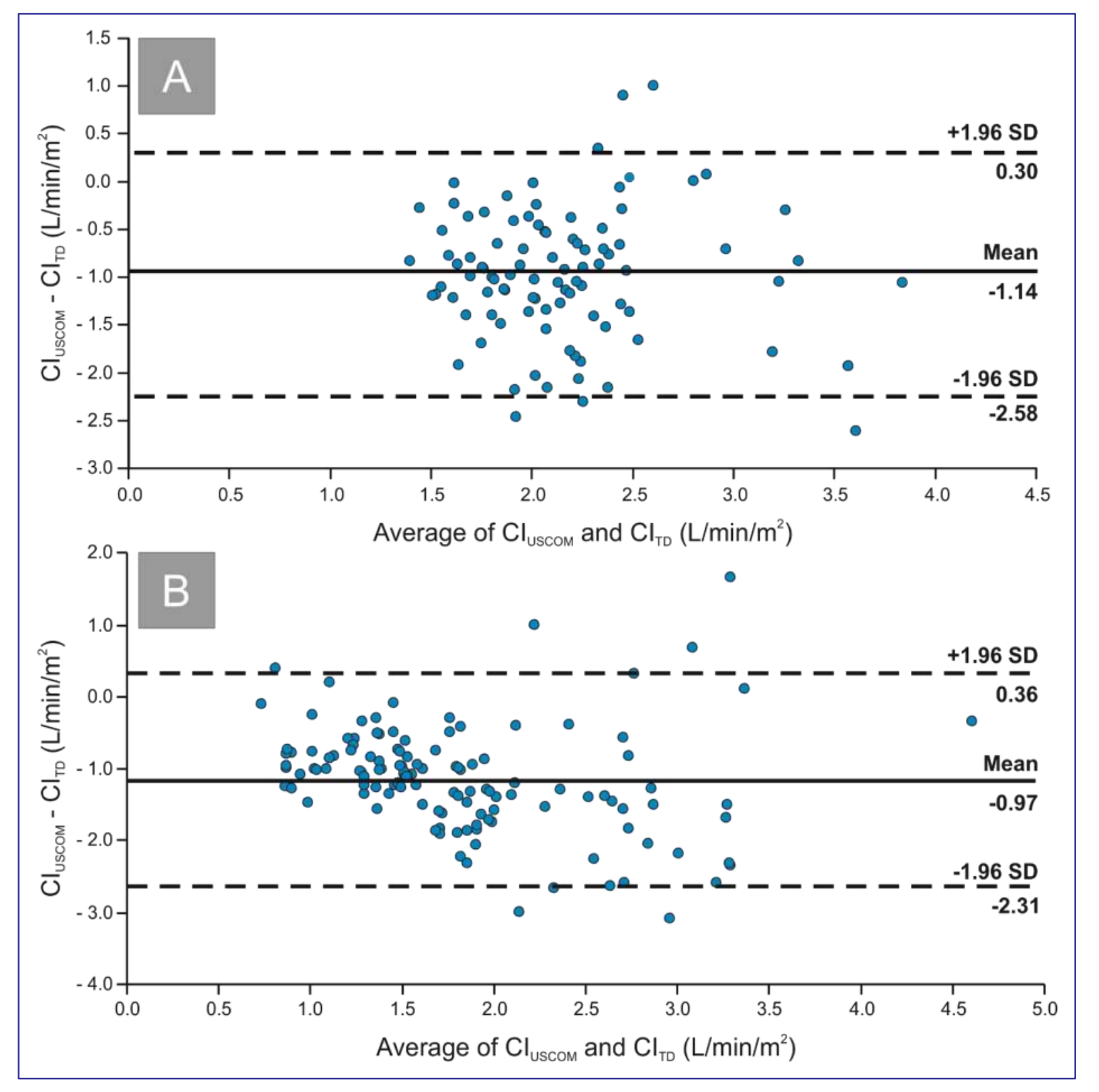

\section{Fig.2}

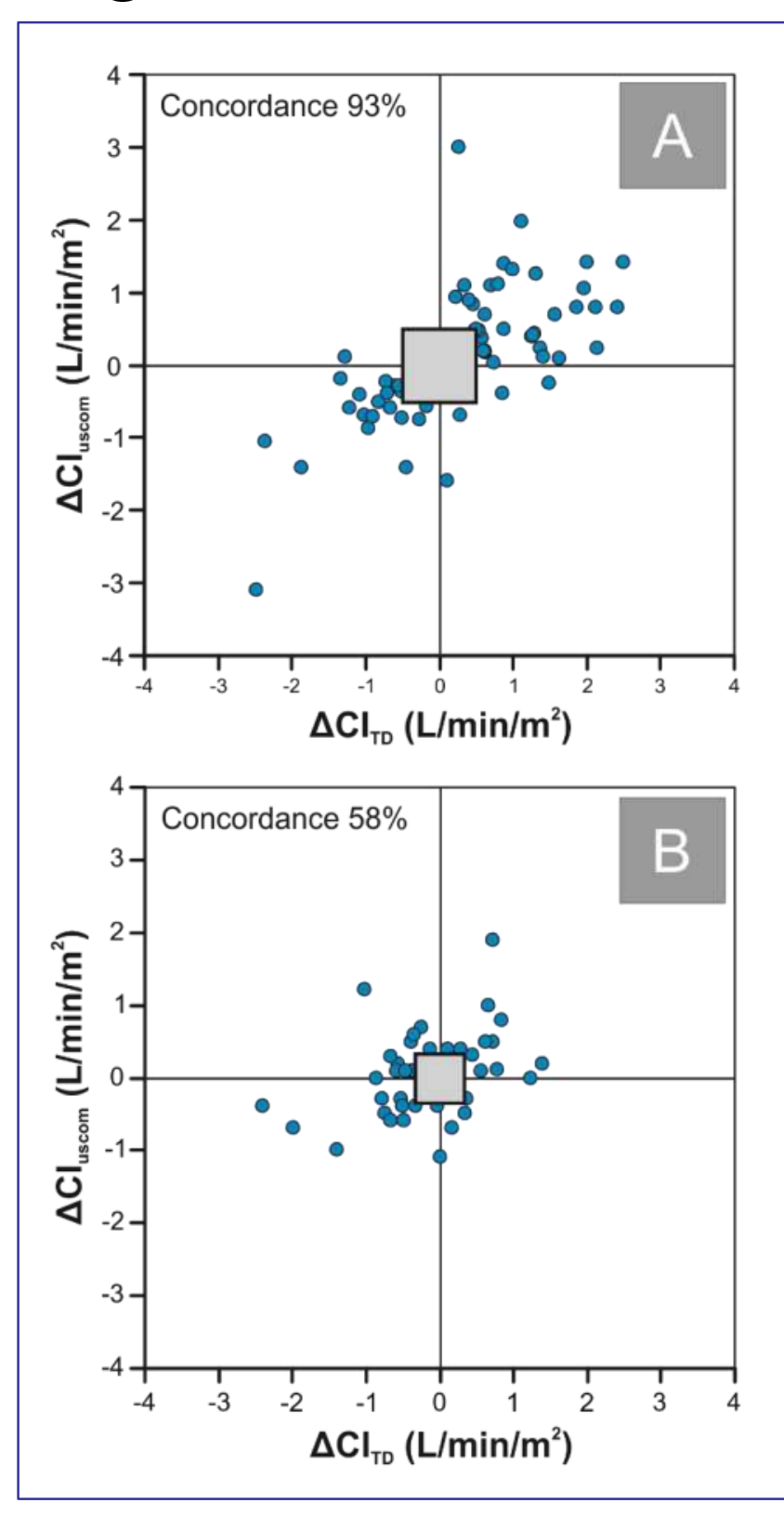

Fig.1

Bland - Altman plots for cardiac index determined with USCOM and prepulmonary thermodilution during mechanical ventilation (A) and after tracheal extubation (B). The continuous horizontal line indicates the value for the average difference between $\mathrm{Cl}_{\text {Uscom }}$ and $\mathrm{Cl}_{\text {TD }}$.

The dashed horizontal lines indicate the upper and lower $95 \%$ limits of agreement. Cluscom - cardiac indexmeasured using USCOM, ClTD - cardiac indexmeasured using prepulmonary thermodilution, SD standard deviation.

\section{Fig.2}

Four-quadrant plot representing the ability of USCOM to track changes in cardiac index during mechanical ventilation $(\mathbf{A})$ and after tracheal extubation (B).

Gray square represents central exclusion zone of $\Delta \mathrm{Cl}<10 \%$.

$\Delta \mathrm{Cl}_{\text {USCOM }}$ - change in cardiac index measured by USCOM, $\Delta \mathrm{Cl}_{\mathrm{TD}}$ - change in cardiac index measured by prepulmonary thermodilution.

\section{Results}

Totally, 231 pairs of data were collected. We found significant correlation between $\mathrm{Cl}_{\mathrm{USCOM}}$ and $\mathrm{Cl}_{\mathrm{TD}}$ in overall data ( $r h o=0.53, p<0.01$ ) and during mechanical ventilation ( $r h o=0.57, p<0.01$ ), but there was no correlation during spontaneous breathing ( $r h o=0.371, p=0.79$ ). Bland-Altman analysis revealed bias between $\mathrm{Cl}_{\text {UScom }}$ and $\mathrm{Cl}_{\mathrm{TD}}$ of $-1.07 \mathrm{~L} / \mathrm{min} / \mathrm{m}^{2}$ with limits of agreement of $\pm 1.40 \mathrm{~L} / \mathrm{min} / \mathrm{m}^{2}$ and percentage error of $72 \%$. The subgroup assessment found better between the method agreement during mechanical ventilation compared to stages after tracheal extubation (Fig. 1) with percentage error of $80 \%$ and $61 \%$, respectively. Trending analysis revealed overall concordance of $81 \%$. The subgroup analysis also showed better trending ability of USCOM during mechanical ventilation (Fig. 2).

\section{Conclusions}

Despite significant correlation between $\mathrm{Cl}_{\mathrm{UScOM}}$ and $\mathrm{Cl}_{\mathrm{TD}}$ during mechanical ventilation after off-pump coronary surgery, USCOM demonstrates poor accuracy with underestimation of $\mathrm{Cl}$, as well as low trending ability compared to thermodilution technique both before and after tracheal extubation. 